\title{
Educação e modernização do Sertão - município, escola, cidade
}

\section{Education and Modernization of the Sertão - Municipality, School, City}

Justino Magalhães 
Resumo: A historiografia ainda mesmo a regional tendeu a referirse ao Sertão nordestino como não-história, onde natureza e vida humana se consumiam num ciclo retomado de sobrevivência. Diferentemente, e tal como os estudos interdisciplinares e a historiografia recente têm vindo a demonstrar, o Sertão integra a história do Nordeste numa sequência de ciclos de desenvolvimento da economia e da sociedade brasileiras. Mas também apresenta vida própria, nos aspectos demográfico, econômico, etnográfico, educativo, sociocultural. A roça foi a principal estrutura de propriedade, poder e organização econômica e social. Em contraponto ao nomadismo e à errância, emergiram aldeamentos e locais de comércio fixo. Autarcia, particularmente sob a modalidade de município e urbanismo integram a modernização do Sertão, onde a educação trouxe um sentido para o progresso através da aculturação escrita, da alfabetização e da escolarização de novos modos e destinos de vida. Neste estudo, após um enquadramento sobre a história do Sertão, apresenta-se uma linha de progresso que inclui o desenvolvimento econômico, agrícola e industrial, a aculturação escrita, o urbanismo, o municipalismo. Na sequência, apresentase um breve historial dos municípios de Delmiro Gouveia e Paulo Afonso.

Palavras-chave: História da educação no Brasil; História do sertão; Cultura escrita; Urbanismo; Municipialismo.

Abstract: Historiography, even regional, tended to refer to the Northeastern Sertão as non-history, where nature and human life were consumed in a resumed cycle of survival. In contrast, and as interdisciplinary studies and recent historiography have shown, Sertão integrates the history of the Northeast in a sequence of development cycles of the Brazilian economy and society. But it also has a life of its own, in demographic, economic, ethnographic, educational, sociocultural aspects. The farm was the main structure of ownership, power and economic and social organization. In contrast to nomadism and wandering, villages 
and places of fixed commerce emerged. Municipality, particularly under the modality of municipality and urbanism, is part of the modernization of the Sertão, where education brought a sense of progress through written acculturation, literacy and schooling in new ways and destinations of life. In this study, after framing the history of the Sertão, a line of progress is presented that includes economic, agricultural and industrial development, written acculturation, urbanism, municipalism. Following, a brief history of the municipalities of Delmiro Gouveia and Paulo Afonso is presented.

Keywords: History of education in Brazil; History of the sertão; Written culture; Urbanism; Municipalism. 


\section{Introdução}

Há uma historiografia que tem descrito e interpretado o Sertão como não-lugar. No Sertão, natureza e vida humana consumiam-se num exercício de sobrevivência e negação de futuro. Também cronistas e memorialistas retrataram quadros drásticos de resiliência e desenlace: abnegação ou partida. O Sertão tem história, história(s) com vida própria, densas, evolutivas, complexas, que incluem itinerância, agricultura, mercado, domínio e libertação, organização da propriedade e relações de produção, campo e cidade, força humana e mecanização, estagnação e progresso. É uma história de interação e construção, assinalada por artefatos, etnografias, etologias, interdependência, solidariedade, culturas, modos de viver, comunicar, articular-se.

O Sertão integrou-se nos ciclos da economia (pecuária, couros, algodão, artesanato, turismo) do Brasil Moderno, em quadros de permanência e mudança. No contraponto e em resposta à exteriorização, também ali se observam manifestações e práticas de fechamento, autarcismo, tradição. Distantes do litoral, cobertos de cerrado ou mato e caatinga, os sertões condicionaram a vida humana. No sertão a criação de gado, a extração e a mineração sobrepunham-se à agricultura. Perduravam tradições e costumes. Refere Victor Leonardi (1996) que “viver no ‘sertão bruto' (sertão sem moradores, completamente desabitado, ou pouco habitado) não é o mesmo do que morar nas zonas rurais próximas de Salvador, de Recife e do Rio de Janeiro"cf. Leonardi, 1996, p. 152. Sobrevivência e progresso foram desafios ao potenciamento do local, a uma identidade inventiva, multiétnica e multicultural. Mas o sertão não é uniforme, nem ficou indiferente aos quadros civilizacionais moderno e contemporâneo. Terra de conflitos, ali cresceram laços de solidariedade e manifestações espirituais: éticas, estéticas, de humanitude e envolvimento colectivo. Assinala Victor que, no sertão, nasceu uma grande parte da cultura brasileira. Com efeito, reitera "o Brasil não teria hoje o perfil cultural que tem se suas dimensões fossem bem menores e em sua história não tivessem entrado seus vários sertões (do Mato Grosso, do Nordeste, de Minas Gerais, de Goiás, da Amazônia) como componentes socioculturais significativos" (LEONARDI, 1996, p. 152).

A representação externa do Sertão tem oscilado entre perspectivas sincréticas de arcaísmo e uniformidade, e referências, localizadas umas e gerais outras. Refletindo distintas conjugações de factores, a etnografia, a arte, a literatura registam assimetrias, temporalidades, metamorfoses. Em Vidas Secas, de Graciliano Ramos (1938), Sinhá Vitória, principal personagem 
feminina, dá vida a uma mulher hábil no domínio das contas, inconformada, alimentando o sonho de um futuro de abundância e conforto. $O$ romance traça um retrato duro do Sertão, mas entretece também um quadro de transformação e mudança, em que a cidade e a escola trazem vida, melhoria econômica, festa e lazer. Quando Fabiano, Sinhá Vitória e os meninos foram à festa de Natal na cidade "Comparando-se aos tipos da cidade, Fabiano reconhecia-se inferior" (RAMOS, 1938, p. 124). Infere Violante Magalhães (2009, p. 96) que os meninos, filhos de Fabiano e Sinhá Vitória, surgem em Vidas Secas com "a função de prenunciar a repetição cíclica da miséria”; mas são também “um contraponto eufórico às situações de fome, privações e perdas que todos vivem” e o móbil para os pais encetarem a fuga em direção a um mundo outro. Como se lê no Cap. XIII, estes "andavam para o Sul, metidos naquele sonho. Uma cidade grande, cheia de pessoas fortes. Os meninos em escolas, aprendendo coisas difíceis e necessárias" (MAGALHÃES, 2009, p. 199).

A história do Sertão regista tempos lentos e tempos de aceleração, ciclos de miséria e abundância.Permanência e mudança, internalidade e exterioridade são binômios onde ressalta a vitória do humano, na dialéctica de quadros espáciotemporais, econômico- técnicos, socioculturais, antropológicos. Ao interrogarse sobre complexidade, permanência, mudança, a historiografia reserva à educação a transformação e a humanização, agindo individualmente ou em coletivo. A educação capacita o humano com ideação, vontade e determinação, meios de intelecção, racionalidade e fabrico. Em consequência, e retomando em Vidas Secas, o carácter e o modo de agir do protagonista, Fabiano, para este, a educação integra a vida e a história do Sertão: “Aí Fabiano baixou a pancada e amunhecou. [...] Era bruto, não fora ensinado. Atrevimento não tinha, conhecia o seu lugar. [...] como não sabia ler (um bruto, sim senhor), acreditara na sua velha. Mas pedia desculpa e jurava não cair noutra” (RAMOS, 1938, p. 151).

Na história do Sertão moderno, a educação integra e dá sentido à aculturação escrita, à escola, aos modos e destinos de vida. Em Grande Sertão: Veredas (1956), Guimarães Rosa contrapõe iletrado e letrado. Pela voz do protagonista Riobaldo, fica-se a saber que o padrinho deste o preparou para as armas e as letras. Será tal decisão uma reminiscência da tradição cavaleiresca, que combinava armas e letras? Com efeito, desde o século XVII que a literatura de cordel do Sertão contém glosas das Novelas de Cavalaria. Mas, por certo, Guimarães Rosa dá preferência à modernização e a um quadro existencialista, bem ilustrado pelas sucessivas mutações de Riobaldo. Este nasceu e passou a infância mergulhado na pobreza. Na adolescência, sob orientação do padrinho, 
foi introduzido, em simultâneo, às armas e às letras. Tornou-se auxiliar do mestre de letras e professor de Zé Bebelo, fazendeiro, em cujo bando se tornou chefe de jagunços, convictos, um e outro, que poriam fim ao cangaço, pois que "Sertão é onde manda quem é forte, com as astúcias [...] Deus mesmo, quando vier, que venha armado [...] Mas só do modo, desses, por feio instrumento, foi que a jagunçada se findou" (ROSA, 1956, p. 19).

Num diálogo com Quelemén, Riobaldo dá nota da aculturação escrita no Sertão:

\begin{abstract}
Compadre meu Quelemén [...] sou só um sertanejo, nessas altas ideias navego mal. Sou muito pobre coitado. Inveja minha pura é de uns conforme o senhor, com toda leitura e suma doutoração. Não é que eu esteja analfabeto. Soletrei, anos e meio, meante cartilha, memória e palmatória. Tive mestre, Mestre Lucas, no Curralinho, decorei gramática, as operações, regra de três, até geografia e estudo pátrio. Em folhas grandes de papel, com capricho tracei bonitos mapas. Ah, não é por falar: mas, desde do começo, me achavam sofismado de ladino. E que eu merecia de ir para cursar latim, em Aula Régia - que também diziam. Tempo saudoso! Inda hoje, apreceio um bom livro, despaçado. Na fazenda O Limãozinho, de um meu amigo Vito Soziano, se assina desse almanaque grosso, de logogrifos e charadas e outras divididas matérias, todo ano vem. Em tanto, ponho primazia é na leitura proveitosa, vida de santo, virtudes e exemplos missionário esperto engambelando os índios, ou São Francisco de Assis, Santo Antônio, São Geraldo[...]. Eu gosto muito de moral. Raciocinar, exortar os outros para o bom caminho, aconselhar a justo (ROSA, 2019).
\end{abstract}

Junto do padrinho, Riobaldo havia percebido que saber ler era útil e conveniente para decifrar contratos, recibos de pagamento, mas não era menos necessário saber manejar as armas. Uma vez escolarizado, foi ajudante de professor e professor, e, por algum momento, desempenhou função de secretário amanuense. Comprometido com Zé Bebelo, a vida empurrou-o para o Cangaço. Compunha versos, mas desde cedo se convenceu que o texto é aferido pela vida: "Eu desde aquele tempo, eu já achava que a vida da gente vai em erros, como um relato sem pés nem cabeça” (ROSA, 2019, p. 232). Por fim, tornou-se fazendeiro e protetor da plebe rural de onde provinha. Se, em menino 
e como jagunço, pertenceu à plebe rural, em jovem e quando velho, incorporou a camada dominante. A aculturação escrita e a escola favoreceram nele uma “distância crítica para perceber a ambiguidade da condição de pobre, pacífico ou guerreiro conforme sirvam aos interesses de quem manda” (GALVÃO, 1972, p. 12$)^{2}$.

Assim pois, educação, aculturação escrita, escolarização integram o complexo de modernização do Sertão, nos planos individual, comunitário, institucional. A história da educação é um contributo fundamental para a história do Sertão. Refletindo um gradual de proximidade e cientificidade, a historiografia relativa ao Sertão, inclui crônicas, memórias, histórias, mas desafia a uma narrativa histórica integrada ${ }^{3}$.

\section{Do Sertão no Brasil Nação}

Na economia do Sertão, as boas terras foram destinadas ao café e ao açúcar, enquanto a criação massiva de gado foi resultante de uma expansão de capital. Uma estimativa datada de 1943 referia que, socialmente, há duas classes no Sertão: os proprietários e os moradores ou agregados, podendo estes representar 80\% do total (GALVÃO, 1972, p. 37). Na sociedade tradicional, aos grandes proprietários, comerciantes, funcionários e escravos contrapunham-se uma plebe desafortunada e outros ocupados em atividades marginais e esporádicas. A fazenda constituía a célula econômica “mínima”, que o fazendeiro chefiava e defendia, num quadro de guerra privada. O contrato como "fazendeiro morador", com direito a fabricar uma pequena agricultura de subsistência, era verbal e de relação pessoal. O “fazendeiro morador" poderia ver esse contrato suspenso em qualquer momento, tendo de partir à busca de nova oportunidade. Fabiano, personagem principal de Vidas Secas, porque não possuía roça, repartia os bezerros e os cabritos com o amo, "e apenas se limitava a semear na vazante uns punhados de feijão e milho, comia da feira, desfazia-se dos animais” (RAMOS, 1938, p. 149). Quando não tinha mais para vender, endividava-se; vivia com medo de ser expulso da fazenda. Com efeito,

a roça mantinha-se como comunidade tipicamente não-estratificada, desenvolvendo com o mercado, ou seja, o capital comercial, uma relação de subordinação e dependência, e transferindo aos grupos que lhe são externos o potencial de acumulação, essencialmente reprodutivo (BARBOSA, 2008, p. 274). 
Desde o período colonial, continuando pelo Império, que o Sertão apresentava formas de povoamento e de organização administrativa, instituições de governo e de decisão, comuns a outras regiões do Brasil: sesmaria, aldeamento, assentamento, quilombo, distrito. A estas formas de povoamento e de organização social correspondiam modalidades de domínio e governo com maior ou menor capacidade de decisão interna, em função da autonomia concedida por uma autoridade superior. Constituindo, no essencial, uma prerrogativa de carácter oligárquico, associada à capacidade econômica de mandatário e empregador, e a um poder paramilitar, o coronelismo também existiu no Sertão, tendo-se acentuado na transição do Império para a República.

Tal como sucedeu um pouco por todo o Brasil, foi sob a modalidade de município que o poder local se tornou representativo e dinâmico, quer no plano interno quer junto dos poderes estadual e federal. Em torno dos municípios ficaram registadas transformações significativas de modernização, nos diferentes aspectos da realidade, com relevo para o educativo e o escolar. Alguns municípios resultaram da evolução de modalidades primárias de povoamento e socialização, consignando um complexo composto por uma população; um território formado por núcleo urbano e campo; um poder colectivo com prerrogativas de justiça, instituição e reconhecimento de regras e bons costumes; um poder executivo, enfim, uma escrituração, uma representação, uma soberania.

Com a independência e a criação formal de um quadro de instituições para o exercício eleitoral do poder político, as instituições de base foram sendo ajustadas. No Império e na República, o município foi instância de descentralização, ainda que os senhores locais tendessem a aliar-se a grandes partidos estaduais ou nacionais, arrastando o poder local para uma disputa entre partidos: o do governo e o da oposição. Em consequência, a população rural continuou a ser arregimentada por grandes proprietários (cf. OLIVEIRA VIANNA, 1955 apud GALVÃO, 1972, p. 45). Todavia, como se verá, aculturação escrita, progresso, municipalização, urbanização foram manifestações fundamentais de desenvolvimento autônomo e de integração do Sertão no Brasil moderno. Assim sucedeu com Delmiro Gouveia e Paulo Afonso, municípios do vale interior do Rio São Francisco e que constituem objeto principal do presente texto.

A integração do Sertão no Brasil moderno e no Brasil Nação, para além do municipalismo, ficou assinalada por acontecimentos de grande simbolismo nacionalista e por episódios trágicos. Entre os primeiros relevam as viagens 
do Imperador Pedro II, nacionalizando, através da viagem, da presença e da inscrição de sinais de pertença, locais de relevo histórico. Um dos locais que visitou e onde deixou sinais de pertença foi a Cachoeira Paulo Afonso. Ali registou um apontamento escrito, considerando o lugar aprazível, de rara beleza e com futuro. Municipalismo e viagem do Imperador assumem relevância na inscrição geográfica, econômica e de desenvolvimento do Sertão no Brasil moderno.

Mas a nacionalização e a modernização incluíram também episódios trágicos e significativos na história da região e na consolidação do Estado-Nação. Foi o que sucedeu com a anexação sangrenta de Canudos, no início da República. Produto de grande mobilização de natureza confessional, o arraial religioso de Belo Monte, mais conhecido por Canudos, foi fundado por António Vicente Mendes Maciel (António Conselheiro), em 1893. No curto período de 4 anos posto que foi anexado em 1897 -, em torno deste centro religioso, instalado numa região pobre e inóspita, cresceu de forma exponencial uma população residente, havendo atingido 5 mil casas e 20 a 25 mil habitantes. Acusada de rebeldia, a povoação foi submetida através da ocupação militar após uma sequência de ataques e de combates, que culminou com o morticínio de residentes e de jagunços. Nessa chacina, os soldados governamentais fizeram uso de um canhão. Narrando o trágico acontecimento de Canudos, em Os Sertões (1902/1985), Euclides da Cunha caracterizou o Sertão de “terra ignota” e fez contraste entre arcaísmo e progresso, num discurso híbrido de crônica e opinião. Sobre aquela carnificina em lugar remoto, comentou "Ademais, não havia temer-se o juízo tremendo do futuro. A História não iria até ali” (CUNHA apud VENTURA, 2019, p. 256).

Oaniquilamento deCanudos àmão da República nacionalista euniformizadora assinala, porventura, a viragem na integração e nacionalização do Sertão. Tomado como hinterland, através deste acontecimento dramático que levou o exército a disparar contra os próprios brasileiros, por ordem governamental e estadual, com concordância da própria Igreja Católica, o Sertão foi atraído para o interior da Nação. Todavia, como referido, vindo de movimentações eleitorais anteriores, com a República tendeu a acentuar-se, particularmente no Sertão, um regime de coronelismo, no qual mandatários locais agiam com poder paramilitar, influenciando do modo decisivo os quadros eleitorais ${ }^{4}$. Foi, todavia, sob a modalidade de município que a modernização administrativa melhor se ajustou às realidades locais e regionais, como ilustram os casos de Delmiro Gouveia e Paulo Afonso. 
Em 1913, entrou em funcionamento a Usina de Angiquinho, primeira instalação hidroelétrica na Cachoeira Paulo Afonso. O empreendimento foi uma iniciativa de Delmiro Augusto da Cruz Gouveia, industrial e comerciante de couros de bovino e peles de caprino, que fundou também a Agro Fabril Mercantil, fábrica de linhas Estrela, no local da Pedra. A vila operária recebeu o nome de Pedra de Delmiro Gouveia. A área urbanizada, incluindo a vila operária, foi organizada e beneficiada com escolas, mercado, salão de cinema. A primeira escola entrou em funcionamento em 1913.

Aquela localidade foi elevada a distrito, através do Decreto-Lei n. ${ }^{\circ} 846$ de 01 de novembro de 1938, da Intervenção Federal. Em 30 de dezembro de 1943, em virtude do Decreto-Lei n. ${ }^{\circ} 2902$ que fixou a divisão administrativa e judiciária do Estado de Alagoas, recebeu a denominação vila de Delmiro Gouveia. O município veio a ser criado e emancipado em 16 de junho de 1952, pela Lei n. ${ }^{\circ}$ 1623, como desmembramento de Água Branca. A sede do novo Município foi a vila Delmiro, entretanto elevada a cidade - cidade Delmiro Gouveia. A cidade continuou a expandir-se como centro comercial e de serviços, além de cidade operária. A importância do elemento urbano sobre a evolução histórica do Brasil, nomeadamente a formação de grandes metrópoles, foi assinalada por Sérgio Buarque de Holanda, nos seguintes termos:

\footnotetext{
No Brasil, onde imperou, desde tempos remotos, o tipo primitivo da família patriarcal, o desenvolvimento da urbanização - que não resulta unicamente do crescimento das cidades, mas também do crescimento dos meios de comunicação, atraindo vastas áreas rurais para a esfera de influência das cidades - ia acarretar um desequilíbrio social, cujos efeitos permanecem vivos ainda hoje (HOLANDA, 2002, p. 145).
}

A denominação Paulo Afonso recupera o nome de Paulo Vieiros Afonso, donatário da Sesmaria Paulo Afonso, que obteve por Alvará Régio de 3 de Outubro de 1725. A concessão incluía a cachoeira. Passagem de boiadas, o local tornou-se povoamento permanente e sede de um comércio fixo, servindo regularmente os autóctones e os transeuntes. Desde 1948 que Paulo Afonso é sede principal da Companhia Hidroelétrica de São Francisco (CHESF). Foi elevado a distrito do município da Glória pela lei estadual (lei n. ${ }^{\circ}$ 628), de 30 de dezembro de 1953, e à categoria de Município, por lei estadual de 28 de julho de 1958 (lei n. ${ }^{\circ}$ 1012). 
A municipalização destes dois centros industriais foi reconhecimento e consolidação de um desenvolvimento integrado, nos planos demográfico, técnico, escolar, urbanístico. A consignação legal e formal do estatuto de município faz jus ao processo autonômico que cedo ali foi frutificando; gera expectativa e é condição para maior desenvolvimento. A industrialização trouxe transformações profundas no binômio rural urbano. Escolarização, urbanismo, industrialização trouxeram uma aceleração na transição para o mercado de trabalho. No Nordeste, tais transformações foram lentas e haviam começado mesmo antes da Abolição da Escravatura por meados do século XIX. $\mathrm{O}$ assalariamento, substituindo-se às relações laborais assentes nos vínculos patriarcais, foi sendo implementado na produção algodoeira e expandiu-se na transição para o século XX (cf. BARBOSA, 2008, p. 146).

\section{Modernização do Sertão}

Datam da última década do século XIX as primeiras tentativas de aproveitamento hidroelétrico da Cachoeira de Paulo Afonso. Foi por iniciativa de Delmiro Gouveia, instalado na localidade da Pedra, que foi inaugurada, em 26 de janeiro de 1913, uma hidroelétrica de 1.550 HP - Usina Hidroelétrica de Angiquinho. A energia foi transportada até ao local da Pedra para alimentar a Agro Fabril Mercantil, grande fábrica de linhas de cozer Estrela, e iluminar o aglomerado urbano. As obras da Usina haviam tido início em 1911, e as da fábrica de linhas Estrela, em 1912. O habitat urbano da Pedra era composto por “258 residências, escolas e espaços de lazer” (NASCIMENTO, 2015, p. 142). Desde 1913 que o núcleo urbano e a fábrica dispunham de abastecimento natural de água, recolhida na Cachoeira de Paulo Afonso e encaminhada por efeito do desnível do terreno. O empreendimento incluiu também a construção de itinerários terrestres para acesso e melhoria da comunicação na região.

A fábrica de linhas Estrela entrou em funcionamento em Junho de 1914, a ela acorrendo sertanejos dos municípios vizinhos, em busca de trabalho. Em 1916, num total de 1.500 operários, havia 700 mulheres, 400 homens e 400 crianças (cf. NASCIMENTO, 2015, p. 142-143). Em tempos de máxima produção, chegaram a trabalhar ali 2.000 operários. Parte do operariado técnico veio de longe. Desde a primeira hora que a educação, a formação dos operários e a especialização dos técnicos (eletricistas, mecânicos, fiadores, tintureiros, chauffers) foi preocupação do empresário e dos chefes intermédios (cf. NASCIMENTO, 2015, p. 147). A fábrica manteve-se em funcionamento após a morte do fundador, em 
1917. Situado junto à estação da linha férrea, o núcleo fabril estava contíguo ao centro urbano, o que facilitava a organização do aglomerado operário. Como referido, desanexado do município de Água Branca, Delmiro Gouveia (vila da Pedra) veio a tornar-se sede de município com o mesmo nome, em 1954.

O processo de urbanização de Paulo Afonso ficou associado ao investimento hidroelétrico da CHESF, que incluiu a instalação de Usinas Hidroelétricas. A chegada de engenheiros e de técnicos à região ditou a necessidade e a urgência de desenvolver um núcleo urbano - Acampamento CHESF -, enquanto o afluxo de operários e de famílias, à procura de trabalho e de melhores condições de vida, deu origem a um aglomerado habitacional de condições precárias, mas em crescimento contínuo - Vila Poty. Emergiu assim um complexo urbano composto por duas realidades contrastantes. Paradoxalmente, o complexo urbano desenvolveu-se com a denominação acampamento (Acampamento CHESF). Era uma área vedada, tendo em frente a Vila Poty. Comportando modos de vida e níveis econômicos e socioculturais distintos, Paulo Afonso desenvolveu-se de modo acelerado acompanhando a expansão da CHESF.

A modernização do Sertão incluiu mutação, metamorfose, (des)virtuamento, transformação e foi frequentemente ditada do exterior. Não foi uniforme e, no campo da educação, a história regista quadros histórico pedagógicos diferenciados, seja pela influência do coronelismo, procurando alimentar uma mão de obra servil ou parcamente remunerada, seja por influência do elemento etno religioso e confessional, seja ainda por determinação de forças desenvolvimentistas. No Sertão de S. Francisco, a perspectiva desenvolvimentista foi concretizada por processos integrados no plano técnico, econômico, educativo. Como assinalado, toma-se para referência a região do Sertão de S. Francisco, onde se destacaram as cidades município de Delmiro Gouveia e Paulo Afonso, aquela associada ao fomento industrial e esta à Central Hidroelétrica de S. Francisco. Num e outro caso, cedo se fizeram sentir as perspectivas autonômicas municipalistas. A municipalização acompanhou um processo integrado de desenvolvimento técnico, demográfico, econômico, urbano, sociocultural. Universalizando a alfabetização e estruturando um complexo educacional modelo, desde as primeiras séries ao ensino colegial e ao ensino profissional, a escolarização acompanhou e deu coerência, sentido e progressão àquele processo de desenvolvimento integrado.

Tomando estes dois estudos de caso, é possível estabelecer uma narrativa histórica, substantiva e significativa em si mesma, e que possibilita compreender e historiar outras regiões do Sertão. O Município como instância de poder 
local e em representação estadual e federal, a cidade como atracão e modelo, a escola como instância de transformação e mobilização, tornaram irreversível a modernização do Sertão ${ }^{5}$.

O que houve de cumulativo e historicamente decisivo nos distintos processos, que incluem modalidades de povoamento e organização, manifestações religiosas, ciclos de economia agrícola, industrialização, comércio, urbanismo? Que convergência entre a entrada em funcionamento da usina hidroelétrica, a fábrica de linhas de Delmiro Gouveia, a central da CHESF, o complexo escolar? A interpenetração do Sertão foi conseguida através dos rios, trilhas e, progressivamente, por alguns troços de ferrovia e por estradas. A integração pós-colonial do Sertão no Brasil Estado foi lenta e conflituosa. A contraposição e superação do coronelismo, com raízes no mandonismo do período colonial e do Brasil Império, e reconfigurado num agenciamento local de oligarcas e clientes, no quadro da República, foi interrompido e ultrapassado pelo municipalismo.

A emergência de comunidades que buscavam reconhecimento e soberania, algumas das quais evoluíram de sesmaria, aldeamento, quilombo, distrito para município cidade, constitui uma associação entre desenvolvimento e poder local. A soberania do local consolidou-se com um poder colectivo, de representação e autonomia - o concelho e, posteriormente, o município. Tal evolução corresponde a um processo integrado no plano econômico, social, político, cultural, educativo. Foi com a industrialização moderna (nacional e internacional) de grande escala, capitalista, associada à escolarização e ao urbanismo, que a modernização do Sertão se tornou irreversível.

\section{Sertão e desenvolvimento integrado - escola, município, cidade}

A criação de escolas acompanhou a fundação da vila da Pedra e da fábrica de linhas Estrela, seja por parte de Delmiro Gouveia, localmente denominado Coronel Delmiro, seja por parte das autoridades estaduais que asseguravam a colocação e o pagamento das professoras. Em consentâneo, com a fundação da fábrica de linhas Estrela, Delmiro Gouveia providenciou a fundação de escolas, a que acorriam as crianças com mais de 5 e 6 anos.

A inscrição das crianças nas escolas era obrigatória para os filhos dos operários, que estavam obrigados a informar a gerência da fábrica sobre a frequência e o aproveitamento escolar dos filhos. Delmiro Gouveia estatuiu prêmios para os melhores alunos. Incumbiu Adolpho Santos, gerente da fábrica, de acompanhar o funcionamento das escolas. Os estudantes aprendiam a leitura 
e a escrita; entoavam o hino nacional do Brasil; participavam de manifestações cívicas. Em 1924, foi inaugurado o Grémio Literário. Quando do afastamento dos herdeiros de Delmiro Gouveia da Direção da Empresa, em 1926, estavam em funcionamento as seguintes escolas: Externato Misto S. João; Escola Ruy Barbosa; Escola 13 de Maio; Escola 15 de Novembro; Escola 7 de Setembro; Escola Rio Branco; Escola José de Alencar. O Cine Pedra, inaugurado em 1915 e onde havia sessões cinematográficas dominicais, também servia de escola nos dias de semana (cf. NASCIMENTO, 2015, p. 174). Havia aulas noturnas para os adultos.

Em 1920, das 12 escolas existentes no Município de Água Branca, metade estavam na vila da Pedra. Entre 1918 e 1930, circulou entre a população operária e urbana o periódico Correio da Pedra, editado pela Companhia Agro Fabril Mercantil e que, além do noticioso, tinha um ideário definido: apelar à cultura cívica e política; denunciar o analfabetismo e a ausência de escolas; denunciar a ausência de práticas de higiene; apresentar o progresso e a urbanidade como contraponto ao arcaísmo. Em resposta ao crescimento do número de alunos, em 1929, foi criada, na perspectiva de Grupo Escolar, a Escola Delmiro Gouveia, que progressivamente recebeu crianças das outras escolas da vila, para prosseguimento de estudos. O Grupo Escolar Delmiro Gouveia veio a ser oficialmente inaugurado em 1943. Estavam então inscritos 340 alunos no conjunto dos três primeiros anos (cf. NASCIMENTO, 2015, p. 240-241). Este ato consignou, por fim, a transferência para a esfera estadual da instrução.

A alfabetização e a formação especializada combinavam-se com modos de vida urbanos e novas formas de viver e relacionar-se. Além da regularidade e da normatividade escolar, havia cortejos e manifestações cívicas, sessões de cinema. A fábrica de linhas Estrela dispunha de banda de música. À fábrica e à vila da Pedra acorriam técnicos e visitantes de diferentes regiões do Brasil e do estrangeiro. Há notícia de estudantes que foram enviados como bolseiros ao exterior. Entretanto, a vila integrava o município de Água Branca, mas desde 1915 que Delmiro Gouveia havia obtido autorização da Prefeitura para funcionamento de uma feira dominical e para instalação de estabelecimentos comerciais.

Foi no contexto desenvolvimentista de meados do século passado que, em sequência da instalação e da atividade da CHESF no vale de S. Francisco para explorar as potencialidades hidroelétricas da Cachoeira de Paulo Afonso, no núcleo habitacional de Forquilha (atual Paulo Afonso, no Estado do Baía), ali teve lugar um crescimento exponencial, nos planos demográfico, educativo, 
urbanístico com características únicas.

A exploração em moldes industriais do potencial hidroelétrico do Rio São Francisco foi objeto de estudos e pareceres, desde o tempo do Império e depois que foi instalada a Hidroelétrica de Angiquinho na Cachoeira Paulo Afonso. Fundada em 1932, a Companhia Agrícola e Pastoril do São Francisco S. A. deu início a uma nova Central Hidroelétrica a jusante de Paulo Afonso - a Usina de Itaparica, que mais tarde foi transferida para a CHESF. Na década de 40, sendo Ministro da Agricultura do Governo de Getúlio Vargas o engenheiro Apolónio Jorge Sales, que havia estudado a região e havia visitado o empreendimento de Tennessee Valley Authority, nos Estados Unidos da América, o processo de aproveitamento hidroelétrico de Paulo Afonso ganhou novo alento. Fracassado o plano de ampliação da Usina de Itaparica, foi construída uma Usina Piloto, em Forquilha, nas proximidades da Cachoeira Paulo Afonso, que foi entregue à CHESF. Esta Sociedade foi criada em 1945, sendo-lhe confiada a exploração hidroelétrica do Vale de São Francisco, nos termos do Decreto-Lei 8.031 de 3 de Outubro de 1945 e do Decreto n. ${ }^{\circ} 19.706$ da mesma data.

Em 15 de Março de 1948, teve lugar a Assembleia Geral da Constituição da Sociedade Anônima Companhia Hidro Eléctrica do São Francisco (CHESF), destinada à criação de Usinas Hidro Eléctricas. Ainda no ano de 1948, pelo decreto 25.865 de 24 de novembro, foi criado o Parque Nacional Paulo Afonso, cuja área incluía terrenos dos Estados de Alagoas, Baía, Pernambuco. Em 1952, foi criado o Banco do Nordeste do Brasil. A superintendência do processo de desenvolvimento do Nordeste era assegurada pela Superintendência de Desenvolvimento do Nordeste (SUDENE). Até à década de 90, a CHESF construíra as Usinas de Moxotó, Sobradinho, Itaparica, Paulo Afonso I, II, III, IV e Xingó. As Usinas de Paulo Afonso I, II, III e IV entraram em laboração em, respectivamente, 1955, 1967, 1974 e 1979. O conjunto de Usinas Paulo Afonso tornou-se, ao tempo, o maior complexo subterrâneo da América. Esse desenvolvimento repercutiu em diferentes aspectos, até que, nos anos 1990 o Governo do Presidente Fernando Color de Melo instituiu o Programa Nacional de Desestatização - PDD, obrigando à reestruturação de empresas estatais, que passaram a focar-se exclusivamente nas suas atividades específicas. Em consequência, a CHESF foi diminuindo os investimentos em programas educacionais e sociais.

A implantação da CHESF em Paulo Afonso trouxera um crescimento exponencial da população e deu origem a um núcleo urbano - Acampamento CHESF, onde progressivamente foram introduzidas e vivenciadas manifestações 
e formas de vida inspiradas no cosmopolitismo moderno. Por contraste e fora de muros cresceu Vila Poty, comunidade que se manteve no limiar da pobreza. Para corresponder às necessidades e ao modo de viver dos técnicos, funcionários e operários o Acampamento CHESF foi beneficiado com moradias e residências operárias, hospital, escolas, clubes, feira livre, igreja. O Acampamento foi vedado com uma cerca de arame farpado e posteriormente por um muro de betão.

Forquilha, composta por Vila Poty e Acampamento CHESF, fora elevada à condição de distrito do município de Glória, do Estado do Baía, pela Lei estadual n. ${ }^{\circ} 62$ de 30 de dezembro de 1953. Em 1958, dez anos após a instalação da CHESF, Paulo Afonso foi elevado a cidade e a município, formado por aquelas duas comunidades: Vila Poty, com 13.000 habitantes, e Acampamento CHESF, com 4.500 habitantes. Eram comunidades contrastantes e sem comunicação entre si. Mesmo após a criação do Município de Paulo Afonso, em 1958, abrangendo o Acampamento CHESF e Vila Poty, aquele manteve uma denominação própria. A municipalização trouxe uma nova dinâmica, nos domínios da organização urbana, da saúde, da educação, mas a CHESF continuou a determinar a eleição municipal. Com a revisão constitucional de 1967, Paulo Afonso passou à condição de município de segurança nacional, ou seja, essencial à defesa do País, nos planos político, econômico, social.

Entre a década de 50 e a década de 80, o Acampamento CHESF foi sendo sucessivamente ampliado e melhorado com infraestruturas de conforto e bem-estar para engenheiros, técnicos, operários, visitantes. O ritmo de transformação foi ditado pela chegada de moradores, sempre que era lançada uma nova Usina de Paulo Afonso. Em 1952, havia 2 escolas, maternidade, ala hospital para tuberculosos, 3 alojamentos para operários solteiros, alojamento para professoras. Havia equipamentos bancários, Agência de Correios e Telégrafos, Hotel, pista de aeronáutica. A organização e a divisão dos espaços no interior do Acampamento, nomeadamente residências, clubes, áreas de lazer, respeitava a segmentação do capital cultural e econômico. Foi já sob alçado do poder municipal que foi criado e entrou em funcionamento o Hospital Nair Alves de Souza, com sede no Acampamento CHESF. Este hospital atendia também a população de Vila Poty e da região. De idêntico modo, foram feitos investimentos no plano urbano, nas infraestruturas do poder municipal, do comércio e do turismo.

Como referido, na década de 50, Vila Poty, repartida pelo exterior do muro que delimitava um núcleo urbano, rico e moderno, abrigava mais de 10.000 
pessoas, sendo que a maior percentagem (80\%) era formada por mulheres e crianças. Paradoxalmente, continuava a ser designado como Acampamento CHESF, o que era uma cidade - Cidade CHESF. Para Edvaldo Nascimento (2019, p. 84),

A vida na Cidade CHESF se caracterizou pelo estabelecimento do fim de uma vida nômada para parte dos sertanejos que passaram a viver no Acampamento, pelo aprendizado e novos habitus adquiridos através da educação escolar, que geraram mudanças nas pessoas que aceitaram e incorporaram novos habitus e ritos escolares. Nesse sentido, a vida no interior do Acampamento passou a ter um modelo que confrontava com a dinâmica social de fora do Acampamento e do Sertão.

Com efeito, através de um processo integrado de melhoria técnica e econômica, de aculturação escrita e escolarização, de incorporação de ritos escolares e de um ethos urbano, humanizado, a educação no Acampamento CHESF trouxe uma transformação das pessoas. O institucional escolar, associado a outros rituais, tornou-se instituinte de uma educação moderna e de uma modernização antropológica. A frequência e o cumprimento escolares, em idiossincrasia com o modo de viver urbano, tornaram irreversível a mudança. Se a este processo se associar a soberania do local através do município, está assegurado um potencial de desenvolvimento que, no Sertão, como noutros locais do mundo ocidental, assegurou e deu sentido à modernização.

Os estudos sobre alfabetização revelam que, em 1940, mais de $80 \%$ da população do Estado da Baía era analfabeta. Também nos restantes Estados do Nordeste a percentagem de analfabetos, em meados do século XX, era muito acentuada, sendo apontada como principal causa a inexistência de escolas. Assim, em 1941, 51,6\% das crianças de Alagoas em idade escolar não frequentava a escola; 55,3\% no Estado de Sergipe; 56,2\% no Estado de Pernambuco; $72 \%$ no Estado da Baía (cf. NASCIMENTO, 2019, p. 147).

Da modernização do Sertão de São Francisco faz parte a escolarização. Como referido, a industrialização e urbanização do núcleo fabril da Pedra, mais tarde Distrito e Município Delmiro Gouveia, fora, desde 1913, acompanhadas pela existência de escolas. De igual modo, com a chegada dos primeiros técnicos da CHESF à localidade de Forquilha (futuro Paulo Afonso), em 1949, foi criado um primeiro curso escolar para crianças e trabalhadores. Em 1950, a escola estava já 
a funcionar num edifício construído de raiz. Denominado Escola Paulo Afonso, o edifício tinha 732 metros quadrados de área construída. A partir de 1952, foi denominada Escola Adozindo Magalhães de Oliveira, em honra ao primeiro director-administrador da CHESF, entretanto falecido.

Em 1950, a CHESF construíra um edifício anexo à Escola Paulo Afonso (futura Escola Adozindo Magalhães de Oliveira), onde, através de um convênio com o Serviço Nacional de Aprendizagem Nacional (SENAI), passou a funcionar a Escola de Ensino Profissional do Serviço Nacional de Aprendizagem Industrial Delmiro Gouveia. Em 1960, foi criado, como continuidade de estudo e formação de técnicos, o Centro de Formação Profissional Paulo Afonso, a que acorriam estudantes de diferentes regiões do país. Com objectivo análogo, foi criada a Escola Agrícola Simões Lopes.

Em 1952, a CHESF, através da Fundação Educativa Paulo Afonso, criou o Ginásio Paulo Afonso (posteriormente Colégio Paulo Afonso), recorrendo a professores oficiais da Vila Poty e funcionários da CHESF (engenheiros, normalistas, desenhistas, integrantes do Exército, uma professora habilitada pelo Conservatório de Música de Salvador e o pároco do Acampamento). Em 1955, estavam matriculados 1.250 alunos nas 3 escolas da Companhia: Adozindo Magalhães de Oliveira, Murilo Braga, Alves de Souza. Entretanto, o Clube Operário Paulo Afonso organizou um curso de corte e costura e uma escola de bordados.

Em Paulo Afonso, foi assim constituído um complexo de continuidade escolar. Em 1972, a CHESF criou um grupo de trabalho para reformular o ensino nas suas escolas, com vista a um Serviço de Ensino Integrado e à formação de um complexo escolar, nos planos administrativo e pedagógico. Em cumprimento da lei 5692/1971, o $1 .^{\circ}$ grau passou a abranger os níveis primários e ginasial, sendo constituído 8 anos de escolaridade obrigatória, repartidos em 3 níveis: nível I ( $1^{\mathrm{a}}, 2^{\mathrm{a}}, 3^{\mathrm{a}}, 4^{\mathrm{a}}$ séries); nível II ( $5^{\mathrm{a}}$ e $6^{\mathrm{a}}$ séries); nível III ( $7^{\mathrm{a}}$ e $8^{\mathrm{a}}$ séries).

A partir de 1974, o Setor de Ensino Integrado da CHESF adaptou para o $2 .^{\circ}$ grau um currículo profissionalizante na área industrial, com os cursos de Mecânica, Eletrotécnica, Electromecânica e Eletricidade; na área Comercial, com Contabilidade, Secretariado e Administração; na área de Saúde, com os cursos de Enfermagem, Técnico-laboratorista - Análise Clínicas; na área de Agricultura, com Agricultura, Agropecuária e Pecuária.

Em 1978, o complexo educacional da CHESF era formado por 365 funcionários e abrangia 5.500 alunos. Para além de professores, psicopedagogos, orientadores educacionais e supervisores, o quadro escolar incluía "médicos, dentistas, 
auxiliares de escritório, auxiliares administrativos, auxiliares de disciplinas, auxiliares de portaria, auxiliares de comércio, feitores, trabalhadores de campo, serventes, zeladores, jardineiros, cozinheiros, trabalhadores agropecuários" (NASCIMENTO, 2019, p. 218). Este complexo escolar de carácter profissionalizante exerceu influência na política escolar para o Nordeste do Brasil. Na década de 90, todas as escolas da CHESF foram sendo transferidas para o Governo do Estado da Baía, a Prefeitura Municipal e para instituições privadas, com relevo para COLEPA (Colégio Paulo Afonso).

A escolarização foi parte do processo de modernização e porventura "civilizacional" do Sertão, proporcionando uma base cultural organizada em currículo progressivo, um método, rituais e modos de viver e idealizar destinos de vida. Os dois estudos de caso aqui apresentados são ilustrativos de tal evolução e possibilitam estruturar uma narrativa historiográfica densa, representativa, significativa.

\section{Conclusão}

A história do Sertão não é linear, nem uniforme, por mais transversais que se afigurem os motivos constantes de descrições de viajantes, de crônicas e do folclore sertanejo. Também as personagens e as representações literárias e etno culturais ilustram com certa verosimilhança os lugares comuns, mas têm de ser submetidos a tirocínios espácio-temporais e a uma hermenêutica de contextualização e deferimento técnico temporal. A história e, particularmente, a modernização do Sertão foi influenciada por factores exógenos, mas nem estes foram uniformes, nem a externalização e a apropriação dos locais foram comuns. Espaço aberto, o Sertão refletiu o cosmopolitismo em planos de interação com a tradição e as circunstâncias históricas.

Como se expôs neste texto, as transformações materiais, econômicas, técnicas, socioculturais foram determinantes, mas a soberania do local através da escola e do município tornou irreversíveis as transformações de progresso e desenvolvimento. Jaguncismo e coronelismo foram regimes progressivamente minados pelo complexo escolarização, urbanismo, municipalismo. Através da aculturação escrita e do institucional escolar, o interno e o externo, o endógeno e o exógeno combinaram-se num ideário normativo, arquetipal, idiossincrático, entre ritual escolar e habitus humanizado e urbanizado modernos.

Processo integrado, o ideário e o transformacional constituíram uma base de soberania que o município capitalizou. Instâncias de modernização do local 
e do regional externalizaram o processo, abrindo-o através da aculturação escrita ao estadual, ao nacional ao cosmopolita. O ethos letrado e urbano trouxe uma dinâmica social e cultural ao mundo sertanejo. A Pedra, mais tarde cidade Delmiro Gouveia, como também Forquilha/ Paulo Afonso não se ficaram como ilhas de modernização. A elas afluíram feirantes, visitantes, transeuntes atraídos pela cidade, com seu lazer, festa, cultura, economia, forma e estilo de vida. Bailes, eventos cívicos, práticas desportivas, teatro, música, dança são dimensões de um programa civilizatório a que a sociabilidade e mobilidade dos habitantes do Sertão não ficaram indiferentes.

Como escrever a história do Sertão sem a história da educação? E como fazer a história da educação sem levar em linha de atenção a singularidade e transversalidade que decorrem de casos como o de Delmiro Gouveia e o de Paulo Afonso? Neles há um sentido histórico, uma linha de continuidade e um lugar à mudança. A história surge ali como um acúmulo e uma progressão de transformações.

Em Delmiro Gouveia, assiste-se a um processo de desenvolvimento integrado, em que produzir e comerciar, sob a modalidade de empresa e tendo uma fonte energética inovadora e disponível no local, gerou um quadro demográficoeconômico-geográfico que constituiu contexto, potencial e força endógena para avançar no progresso e no crescimento. Observa-se uma economia de diversificação e progressão. A escolarização, o urbanismo, bem como a dinâmica interna de coronelato/ município, legitimados e dando curso a uma soberania, constituíram um complexo histórico.

Quadro análogo se veio a desenvolver em Paulo Afonso, na sequência da instalação da CHESF, que gerou uma cidade contraste com a vila envolvente, num fenômeno de exclusão, mas também de superação e irreversibilidade, quanto a civismo, progresso, humanitude. Enfim, de uma outra educação. $O$ institucional escolar associado ao regime empresarial constituíram aqui uma bildung modelada pela figura do técnico e de engenheiro. O complexo escolar curricular, pedagógico e administrativo, de continuidade, foi adotado como modelo para a escolarização estadual.

A historiografia do Sertão tendeu a oscilar entre a internalidade e exterioridade e entre avanços e paralisações, senão mesmo retornos. O Sertão não é uniforme, mas também não é imutável. Na educação residiu a superação de mundos autárcitos e bélicos por um mundo humanizado, aberto ao progresso. Outros valores e modos de vida, outros profissionais e outros perfis humanos se sobrepuseram a sertanejos, beatos, jagunços. As melhorias técnicas, a 
escolarização e o urbanismo surgem como factores de identidade e mudança. A educação e o institucional escolar fizeram parte desta história. Ao introduzir uma problemática complexa e uma dialéctica entre modernização material, institucional e sociocultural, ao apresentar como conceitos operacionais a escola, o município, a cidade, ao tomar as narrativas desenvolvimentistas de Delmiro Gouveia e Paulo Afonso como representativas e significativas, integradas num quadro conceptual e de desenvolvimento histórico mais amplo, procurei deixar o meu contributo para a História do Sertão.

\section{Referências}

BARBOSA, Alexandre de Freitas. A formação do mercado de trabalho no Brasil. São Paulo: Alameda Casa Editorial, 2008.

BARTELT, Dawid Danilo. Sertão, república e nação. São Paulo: EDUSP, 2009.

CUNHA, Euclides. Os sertões: campanha de canudos. São Paulo: Brasiliense, 1902/1985.

GALVÃO, Walnice Nogueira. As formas do falso: um estudo sobre a ambiguidade no grande sertão: veredas. São Paulo: Editora Perspectiva, 1972.

HOLANDA, Sérgio Buarque. Raízes do Brasil. 26. ed. São Paulo: Companhia das Letras, 2002.

LEONARDI, Victor. Entre árvores e esquecimentos: história social nos sertões do Brasil. Brasília: Paralelo 15 Editores, 1996.

MAGALHÃES, Violante F. Sobressalto e espanto: narrativas literárias sobre e para a infância, no neo-realismo português. Lisboa: Campo da Comunicação, 2009.

NASCIMENTO, Edvaldo Francisco. Delmiro Gouveia e a educação na pedra. 3. ed. Maceió: Imprensa Oficial Graciliano Ramos, 2015.

NASCIMENTO, Edvaldo Francisco. Modernização e educação escolar no nordeste brasileiro: as escolas da Companhia Hidro Eletrica do São Francisco - CHESF (1949-2000). Recife: [s. n.], 2019. Brochura.

NEVES, Erivaldo Fagundes. Crônica, memória e história: formação historiográfica dos sertões da Bahia. Feira de Santana: UEFS Editora, 2016.

RAMOS, Graciliano. Vidas secas: romance. 3. ed. Lisboa: Portugália Editora, 1938. 
ROSA, João Guimarães. Grande sertão: veredas. 22. ed. São Paulo: Companhia das Letras, 2019. Disponível em: https://www.companhiadasletras.com.br/ trechos/14608.pdf. Acesso em: 3 fev. 2020. p. 17

ROSA, João Guimarães. Grande sertão: veredas. São Paulo: Companhia das Letras, 1956.

VENTURA, Roberto. Euclides da Cunha: esboço biográfico. 2. ed. São Paulo: Companhia das Letras, 2019.

\section{Notas}

'Faculdade de Educação, Universidade de Lisboa.

${ }^{2}$ Walnice Nogueira Galvão (1972) adverte para a temática da ambiguidade neste romance de Guimarães Rosa. No entanto, afigura-se convincente que a escola pessoaliza e faz a diferença social, tornando irreversível a mudança.

${ }^{3}$ Para uma perspectiva abreviada da historiografia do Sertão, pode consultar-se Erivaldo Fagundes Neves (2016).

${ }^{4} \mathrm{O}$ significado histórico do acontecimento de Canudos foi estudado por David Bartelt (2009) para quem este episódio dramático rompeu com um Sertão - hinterland de beatos e jagunços.

${ }^{5}$ Este complexo está presente no estudo de Edvaldo Nascimento (2019). 